\title{
Evaluating the Efficacy of Mergers and Acquisitions
}

\author{
*Prof. Jignesh B Patel \\ Assistant Professor, Kalol Institute of Management, KIRC Campus, Kalol- 382721 Gujarat (India)
}

\begin{abstract}
Competition is fierce, and companies must team up to survive in an industry where specialized knowledge is sovereign. One of the largest, most critical, and most difficult parts of a business merger is the successful integration of the enterprise networks of the merger partners. BPO Systems has the expertise and skills to make your merger or acquisition a much smoother process. An attempt has been made to draw the results of only some of the earlier studies while analyzing the causes of failure of majority of the mergers in this exploratory Research paper. Making the mergers work successfully is not that easy as here we are not only just putting the two organizations together but also integrating people of two organizations with different cultures, attitudes and mindsets. While making the merger deals, it is necessary not only to make analysis of the financial aspects of the acquiring firm but also the cultural and people issues of both the concerns for proper post-acquisition integration and to make the combination successful.
\end{abstract}

Keywords: Merger, Acquisitions, BPO, post-acquisition integration

\section{Article Publication}

泴 Published Online: 31-Jul-2021

*Author's Correspondence

8 Prof. Jignesh B Patel

8 Assistant Professor, Kalol Institute of Management, KIRC Campus, Kalol382721 Gujarat (India)

$\triangle$ jigneshpatel2411@gmail.com

C 2021The Authors. Published by

International Journal of Management and Development Studies

This is an open access article under the CC BY-NC-ND license cC (https://creativecommons.org/licenses/b y-nc-nd/4.0/)

\section{Background of the Study}

Mergers and acquisitions are taking place all over the world irrespective of the industry and it is necessary to understand the basic concepts pertinent to this. The term merger involves coming together of two or more concerns resulting in continuation of one of the existing entities or forming of an entirely new entity. When one or more concerns merge with an existing concern, it is the case of absorption. Amalgamation involves the fusion of two or more companies and forming of a new company. Acquisition is an act of acquiring effective control over the assets or management of the corporate without any combination of both of them. When the acquisition is 'forced' or 'unwilling', it is generally called takeover. Though, the terms 'merger', 'amalgamation', 'acquisition' and 'takeover' have specific meanings, they are generally used interchangeably. Mergers may be horizontal, vertical or conglomerate. Further, they may be friendly or hostile. Generally, mergers are friendly whereas tender offers are hostile.

\section{Causes for Failure of Mergers and Acquisitions}

The mergers and acquisitions basically aim at enhancing the shareholders' value or wealth and the results of several empirical studies reveal that mergers and acquisitions consistently benefit the target company's shareholders but not the acquirer company shareholders. A majority of corporate mergers fail. Failure occurs on average, in every sense, acquiring firm stock prices likely to reduce when mergers are announced; many acquired companies sold off; and profitability of the acquired company is lower after the merger relative to comparable non-merged firms. Consulting firms have also estimated that from one half to two thirds of mergers and acquisitions do not come up to the expectations of those transacting them, and many resulted in divestitures. Statistics show that roughly half of acquisitions are not successful. Mergers and acquisitions fails 
quite often and fails to create value or wealth for shareholders of the acquirers. A definite answer as to why mergers fail to generate value for acquiring shareholders cannot be provided because mergers fail for a host of reasons. The following are the major reasons for the failure of the Mergers and Acquisitions:

- Disproportionate premium: In a competitive bidding situation, a company may tend to pay more. Often highest bidder is one who overestimates value out of ignorance. Though he emerges as the winner, he happens to be in a way the unfortunate winner. This is called winners curse hypothesis. When the acquirer fails to achieve the synergies required compensating the price, the mergers and acquisitions fails.

- Size related Issues: A mismatch in the size between acquirer and target has been found to lead to poor acquisition performance. Many acquisitions fail either because of 'acquisition indigestion' through buying too big targets or failed to give the smaller acquisitions the time and attention it required.

- Lack of research before Acquisition: Acquisition requires gathering a lot of data and information and analyzing it. It requires extensive research. A carelessly carried out research about the acquisition causes the destruction of acquirer's wealth.

- Diversification: Very few firms have the ability to successfully manage the diversified businesses. Unrelated diversification has been associated with lower financial performance, lower capital productivity and a higher degree of variance in performance for a variety of reasons including a lack of industry or geographic knowledge, a lack of focus as well as perceived inability to gain meaningful synergies. Unrelated acquisitions, which may appear to be very promising, may turn out to be big disappointment in reality.

- Previous Acquisition Experiences: While previous acquisition experience is not necessarily a requirement for future acquisition success, many unsuccessful acquirers usually have little previous acquisition experience. Previous experience will help the acquirers to learn from the previous acquisition mistakes and help them to make successful acquisitions in future. It may also help them by taking advice in order to maximize chances of acquisition success.

- Unwieldy and Inefficient: Conglomerate mergers proliferated in 1960s and 1970. Many conglomerates proved unwieldy and inefficient and were wound up in 1980s and 1990s. The unmanageable conglomerates contributed to the rise of various types of divestitures in the 1980s and 1990s.

- Poor Cultural Fits amongst Companies: Cultural fit between an acquirer and a target is one of the most neglected areas of analysis prior to the closing of a deal. However, cultural due diligence is every bit as important as careful financial analysis. Without it, the chances are great that mergers and acquisitions will quickly amount to misunderstanding, confusion and conflict. Cultural due diligence involves steps like determining the importance of culture, assessing the culture of both target and acquirer.

- Poor Organizational Fit: Organizational fit is described as "the match between administrative practices, cultural practices and personnel characteristics of the target and acquirer. It influences the ease with which two organizations can be integrated during implementation. Mismatch of originations fit leads to failure of mergers.

- Poor Strategic Fit: A Merger will yield the desired result only if there is strategic fit between the merging companies. Mergers with strategic fit can improve profitability through reduction in overheads, effective utilization of facilities, the ability to raise funds at a lower cost, and deployment of surplus cash for expanding business with higher returns. But many a time lack of strategic fit between two merging companies especially lack of synergies results in merger failure.

- Striving for Vastness: Size no doubt is an important element for success in business. Therefore, there is a strong tendency among managers whose compensation is significantly influenced by size to build 
big empires. Size maximizing firms may engage in activities, which have negative net present value. Therefore, when evaluating an acquisition it is necessary to keep the attention focused on how it will create value for shareholders and not on how it will increase the size of the company.

- Faulty evaluation of the Companies: At times acquirers do not carry out the detailed diligence of the target company. They make a wrong assessment of the benefits from the acquisition and land up paying a higher price.

- Poorly Managed Integration: Integration of the companies requires a high-quality management. Integration is very often poorly managed with little planning and design. As a result, implementation fails. The key variable for success is managing the company better after the acquisition than it was managed before. Even good deals fail if they are poorly managed after the merger.

- Failure to Take Immediate Control: Control of the new unit should be taken immediately after signing of the agreement. ITC did so when they took over the BILT unit even though the consideration was to be paid in 5 yearly instalments. ABB put new management in place on day one and reporting systems in place by three weeks.

- Failure to Set the Pace for Integration: The important task in the merger is to integrate the target with acquiring company in every respect. All function such as marketing, commercial; finance, production, design and personnel should be put in place. In addition to the prominent persons of acquiring company the key persons from the acquired company should be retained and given sufficient prominence opportunities in the combined organization.

- Incomplete and Inadequate Due Diligence: Lack of due diligence is lack of detailed analysis of allimportant features like finance, management, capability, physical assets as well as intangible assets results in failure. ISPAT Steel is a corporate acquirer that conducts mergers and acquisition activities after elaborate due diligence.

- Merger between Equals: Merger between two equals may not work. The Dunlop Pirelli merger in 1964, which created the world's second largest tier company, ended in an expensive divorce. Manufacturing plants can be integrated easily, human beings cannot. Merger of equals may also create ego clash.

- Over Leverage: Cash acquisitions results in the acquirer assuming too much debt. Future interest cost consumes too great a portion of the acquired company's earnings (Business India 2005). That increased Distress cost of Acquirer firm

- Incompatibility of Partners: Alliance between two strong companies is a safer bet than between two weak partners. Frequently many strong companies actually seek small partners in order to gain control while weak companies look for stronger companies to bail them out. But experience shows that the weak link becomes a drag and causes friction between partners. A strong company taking over a sick company in the hope of rehabilitation may itself end up in liquidation.

- Limited Focus: If merging companies have entirely different products, markets systems and cultures, the merger is doomed to failure. Added to that as core competencies are weakened and the focus gets blurred the fallout on bourses can be dangerous. Purely financially motivated mergers such as tax driven mergers on the advice of accountant can be hit by adverse business consequences. The TATA for example, sold their soaps business to Hindustan Lever.

- Failure to Get Figures Audited: It would be serious mistake if the takeovers were concluded without a proper audit of financial affairs of the target company. Though the company pays for the assets of the target company, it also assumes responsibility to pay all the liabilities.

- Failure to Get an Objective Evaluation of the Target Company' Condition: Risk of failure will be minimized if there is a detailed evaluation of the target company's business conditions carried out by the professionals in the line of business. Detailed examination of the manufacturing facilities, product design features, rejection rates, and distribution systems, profile of key people and 
productivity of the workers is done. Acquirer should not be carried away by the state-of-the-art physical facilities like a good headquarters building, guest house on a beach, plenty of land for expansion, etc.

- Lack of Proper Communication: Lack of proper communication after the announcement of mergers and acquisitions will create lot of uncertainties. Apart from getting down to business quickly companies have to necessarily talk to employees and constantly. Regardless of how well executives communicate during a merger or an acquisition, uncertainty will never be completely eliminated.

- Failure of Leadership Role: Some of the role leadership should take seriously are modeling, quantifying strategic benefits and building a case for mergers and acquisition activity and articulating and establishing high standard for value creation. Walking the talk also becomes very important during mergers and acquisitions.

\section{Conclusion}

During last three decades Mergers and acquisitions have become very popular owing to rapid changes that have taken place in the business environment. Business firms now have to face increased competition not only from firms within the country but also from international business giants thanks to globalization, liberalization, technological changes, etc. Generally, the objective of mergers and acquisitions is wealth maximization of shareholders by seeking gains in terms of synergy, economies of scale, better financial and marketing advantages, diversification and reduced earnings volatility, improved inventory management, increase in domestic market share and also to capture fast growing international markets abroad. Mergers and acquisitions are aimed at improving profits and productivity of a company. Simultaneously, the objective is also to reduce expenses of the firm. However, mergers and acquisitions are not always successful. Astonishingly, though the number and value of mergers and acquisitions are growing rapidly, the results of the studies on the impact of mergers on the performance from the acquirers' shareholders perspective have been highly disappointing. In this paper an attempt has been made to draw the results of only some of the earlier studies while analyzing the causes of failure of majority of the mergers. Making the mergers work successfully is not that easy as here we are not only just putting the two organizations together but also integrating people of two organizations with different cultures, attitudes and mindsets. Meticulous premerger planning including conducting proper due diligence, effective communication during the integration, committed and competent leadership, speed with which the integration plan is integrated all this pave for the success of mergers and acquisitions.

\section{References}

Banerjee Gargi, "Year of Deals", Business World, Vol.25, Issue 21, October, 2005, Pp.34-37.

Banerjee Gargi, "How Much Value is created by M\&A Deals in India?" Business World, October 2005, pp.40.

Machhi Hetal, "Merger and Acquisition," The Management Accountant, October 2005, pp. 767-770.

Maheshwari S.N., "Financial Management, Principles and Practices," Sultan Chand \& Sons, New Delhi, 2002, p. E127-E161.

Maitra Dilip, "Mega Money Mergers," Business Today, December 1996, p. 82-93.

Chandra Prasanna, "Financial Management: Theory and Practice", Fifth Edition, Tata Mcgraw-Hill Publishing Company Limited, New Delhi, 2001, p.911-960.

Pawaslar, Vardhana, "Effects of Mergers on Corporate Performance in India," Vikalpa, Vol.26, No.1, JanuaryMarch 2011, pp.19-32.

Prayag Anjali, "M\&Aing It Work", Praxis-Business Line's Journal on Management, October, 2005, pp.34-41.

H V Harish, India Inc goes global (Mergers and Acquisitions), Capital Market, Jan 2016, pp. 5-12. 